\title{
Germinação de sementes e sobrevivência de plântulas de Himatanthus sucuuba (Spruce) Wood. em resposta ao alagamento, nas várzeas da Amazônia Central ${ }^{1}$
}

\author{
Cristiane da Silva FERREIRA², Maria Teresa Fernandez PIEDADE³, Luis Carlos BONATES²
}

\begin{abstract}
RESUMO
Himatanthus sucuuba é uma espécie que coloniza as várzeas na Amazônia Central. O objetivo desse trabalho foi estudar as estratégias de adaptação da planta ao alagamento prolongado dessas áreas. Para tanto, foram acompanhados a germinação das sementes e o desenvolvimento das plântulas, simulando as condiçōes naturais de campo (seca e alagamento). A germinação foi realizada em dois substratos: areia+serragem (não-alagado), e em água (alagado). Durante 120 dias, as plântulas geradas foram submetidas a três tratamentos: controle (irrigação diária), submersão parcial (sistema radicular) e submersão total. Foram analisadas as alterações na morfologia das plântulas, na anatomia das raízes e a atividade da enzima álcool desidrogenase (ADH), nos tempos: 0, 15, 30, 60, 90 e 120 dias. Foi constatado que a espécie apresenta elevada taxa de germinação e produção de plântulas, ambas acima de $80 \%$, mesmo para sementes em água. Sob submersão parcial foram formadas lenticelas hipertrofiadas, raízes adventícias e aerênquima radicular. A atividade da $\mathrm{ADH}$ se manteve elevada até o $60^{\circ} \mathrm{dia}$, com decréscimo após esse período. Plântulas sob submersão total perderam as folhas, não formaram raízes adventícias ou lenticelas, mas desenvolveram aerênquima. Estas plântulas apresentaram os maiores valores da $\mathrm{ADH}$, que permaneceram altos até o término do experimento, indicando o desvio do metabolismo anaeróbico para produção de etanol como principal via para a manutenção da carga energética. Apesar de ter ocorrido a morte de algumas plântulas no tratamento de submersão total, o percentual de sobreviventes foi alto com $70 \%$ ao final dos 120 dias de duração do período experimental. Desta maneira, as plântulas de H. sucuuba modulam morfo-fisiologicamente a tolerância ao alagamento em função do tempo de exposição ao estresse e altura da coluna de água.
\end{abstract}

\section{PALAVRAS-CHAVE}

Inundação, Metabolismo anaeróbico, Álcool desidrogenase, Adaptações morfológicas, Aerênquima

\section{Seed germination and seedling survival of Himatanthus sucuuba (Spruce) Wood., in response to flooding in the varzeas of the Central Amazon}

\begin{abstract}
Himatanthus sucuuba is a tree which colonizes the varzeas of Central Amazonia. The present work was carried out in order to analyze the adaptive strategies of the species to cope with the long periods offlooding common in the varrzea. Seeds were accompanied from germination until the seedling stage, in experimental conditions simulating natural field conditions (terrestrial phase and flooding period). Germination was tested in two substrates: sand + sawdust (only irrigated), and in water (submergence). The seedlings produced were then subjected, for 120 days, to three treatments: control (daily irrigation), partial submersion (root system) and total submersion (whole seedling). Alterations in the morphology of seedlings and in root anatomy were examined, together with the activity of the enzyme alcohol dehydrogenase (ADH) $0,15,30,60,90$, and 120 days after the start of the treatments. Irrespective of the flooding regime, germination rates and seedling formation were high, both above 80\%. Under partial submersion, hypertrophic lenticels, adventitious roots and aerenchyma were formed in the roots while ADH activity remained high until the $60^{\text {th }}$ day of flooding, declining afterwards. Seedlings under total submersion lost all leaves, did not form adventitious roots or lenticels, but developed aerenchyma. These seedlings showed the highest values of ADH, which remained high until the end of the experiment, indicating the diversion of the aerobic metabolism to the production of ethanol as the main pathway to maintain the energetic balance. Although some totally submersed seedlings died, $70 \%$ of them survived the 120 days offlooding. Seedlings of $\mathrm{H}$. sucuuba modulate morpho-physiologically the tolerance to flooding according to the time of exposure to the stress and the height of the water column.
\end{abstract}

\section{KEYWORDS}

Flood, Anaerobic metabolism, Alcohol dehydrogenase, Morphologic adaptation, Aerenchyma.

${ }^{1}$ Parte da dissertação de Mestrado do primeiro autor no curso de Pós-Graduação em Botânica, INPA/UFAM

${ }^{2}$ Estudante de Doutorado do Curso de Pós-Graduação em Botânica, INPA/UFAM (crisbotanica@gmail.com; bonates@inpa.gov.br).

${ }_{3}^{3}$ Pesquisadora MCT/INPA. Projeto INPA/Max-Planck, Av. André Araújo 2936, CP 478 CEP. 69011-970, Manaus, AM (maitepp@inpa.gov.br) 


\section{INTRODUÇÃO}

As enchentes anuais provocadas pelo transbordamento dos rios de água branca e seus afluentes alagam extensas áreas de florestas ao longo da bacia amazônica, as denominadas várzeas (Junk, 1993). A altura média da coluna de água pode chegar a $10 \mathrm{~m}$ e durar até 210 dias (Junk et al., 1989), submetendo as plântulas e a maioria das árvores que habitam esses ecossistemas, a períodos de vários meses de submersão completa (Parolin, 2000; Piedade et al., 2001). O alagamento do solo exerce profundo efeito nos organismos que nele habitam, especialmente nas plantas, por serem sésseis (Piedade et al., 2000). A maioria das sementes de plantas terrestres que possui alta taxa de germinação no solo não germina na água por perder rapidamente a viabilidade sob tais condições (Hook, 1984; Parolin, 2001). O alagamento do solo restringe a disponibilidade de oxigênio para o embrião, necessário para a ativaçāo dos processos fisiológicos que caracterizam a germinação, impedindo-a ou impondo dormência às sementes de muitas espécies (Kozlowski, 1997).

Por outro lado, apesar das características ambientais peculiares da várzea, muitas espécies de árvores crescem naturalmente nessas áreas. Em geral, as plantas que toleram inundaçōes periódicas devem regularmente readaptar seu metabolismo e ciclo de vida modificando a via respiratória de forma a suportar as alteraçōes entre condições aeróbicas e hipóxicas ou até mesmo anóxicas, impostas pelo alagamento (Kozlowski, 1997; Dat et al., 2004). Interações entre adaptações metabólicas e morfoanatômicas, como a formação de raízes adventícias, lenticelas e aerênquima, são comumente citadas na literatura em plantas sob condiçōes de déficit de oxigênio em decorrência do alagamento, tendo tais estruturas a finalidade de propiciar a desintoxicação e/ou captação de oxigênio (Kozlowski, 1997; Dennis et al., 2000; Mielke et al., 2003). A tolerância a essas condiçôes varia, entre outras coisas, com a idade e o tempo de exposição ao alagamento (Kozlowski, 1997; Lytle \& Poff, 2004), de forma que, como padrão geral, o estresse por inundação reduz a diversidade de espécies na várzea (Junk, 1993; Capon, 2005).

Entre as espécies que habitam as áreas inundáveis da Amazônia Central encontra-se a Himatanthus sucuuba (Spruce) Wood., Apocynaceae de nome popular sucuúba ou sucuúba verdadeira. A árvore é lactescente, mede de 8 a $20 \mathrm{~m}$ de altura, com frutos deiscentes e numerosas sementes elipsóides secas, envoltas por uma ala membranosa circular bem desenvolvida. Esta estrutura reveste inteiramente a semente protegendo-a e facilitando a dispersão da espécie pelo vento, anemocoria (Plumel, 1991), e/ou pela água, hidrocoria (Ferreira et al., 2005). Essa espécie distribui-se predominantemente na bacia amazônica (Plumel, 1991), sendo facilmente encontrada na terra firme ou habitando as áreas de várzea em suas porções mais baixas, locais onde a planta pode ser submetida a uma inundação de até seis metros de altura, com a duração de cerca de cinco meses
(Wittmann et al., 2002). A árvore desperta grande interesse na economia regional, especialmente pelo valor fitoterápico atribuído a seu látex (van den Berg, 1984).

No presente estudo, H. sucuuba foi escolhida para ajudar a elucidar os mecanismos adaptativos de plantas ao excesso de água no solo e estabelecer os limites de tolerância das mesmas ao alagamento. Com o objetivo de identificar as estratégias de adaptação da planta em resposta ao alagamento prolongado, foram feitos estudos germinativos e das características morfoanatômicas e metabólicas das plântulas quando inundadas, neste último caso, a atividade da enzima álcool desidrogenase $(\mathrm{ADH})$, associada a anoxia ou hipóxia do sistema radicular.

\section{MATERIAL E MÉTODOS}

\section{GERMINAÇÃO DE SEMENTES E PRODUÇÃO DE PLÂNTULAS}

As sementes foram coletadas de matrizes de diferentes populaçōes em áreas de várzea, na Illha de Marchantaria e cercanias $\left(03^{\circ} 15^{\prime} \mathrm{S}, 60^{\circ} 00^{\prime} \mathrm{W}\right)$, nas proximidades de Manaus, às margens do rio Solimôes. O experimento foi conduzido em viveiro, nas dependências do INPA, em Manaus. Os testes de germinação foram realizados em sementes com e sem a ala que as envolve, com a finalidade de verificar se a remoção da mesma resultaria em um aumento da velocidade da germinação. A retirada da ala foi feita manualmente, deixando a região da micrópila totalmente livre. As sementes foram colocadas para germinar em bandejas de $20 \times 60 \mathrm{~cm}$ à temperatura ambiente (média diária de $28^{\circ} \mathrm{C}$ ) e submetidas a dois diferentes tratamentos, que simularam o ambiente natural da espécie, divididos de acordo com o substrato em: a) não-alagado: serragem + areia lavada (1:1), com regas diárias, e b) alagamento: submersas em uma coluna de água de cinco centímetros. Cada bandeja foi considerada uma amostra e os testes constaram de quatro repetiçōes de 100 sementes, para cada tratamento. A protrusão da radícula indicou a germinação da semente, que depois de germinada permaneceu no substrato correspondente até a formação de uma plântula com cerca de sete centímetros de altura. Após esse período, as plântulas foram transferidas para vasos de polietileno $(19 \times 16 \mathrm{~cm})$, que continham solo da várzea e mantidas em casa de vegetação durante três meses, tempo médio de duração da fase terrestre na várzea, quando então se deu início aos experimentos de alagamento.

\section{EXPERIMENTO DE ALAGAMENTO}

Para simular as condições de submersão, foram utilizados quinze tanques de amianto (1000 l), onde em uma das laterais estava inserido, próximo à base, um tubo de PVC com $40 \mathrm{~mm}$ de diâmetro, com a finalidade de controlar o nível da água. A troca da água foi realizada semanalmente. Dentro de cada tanque foram dispostas seis plântulas de H. sucuuba, sendo uma plântula/ vaso, já estabelecidas em solo de várzea. Durante 120 dias as plântulas foram submetidas a três tratamentos: controle (irrigação diária), submersão parcial (sistema radicular e parte do caulículo 
alagado, coluna de água $\cong 25 \mathrm{~cm}$ ) e submersão total (alagamento total da planta, coluna de água $\cong 70 \mathrm{~cm})$. O delineamento experimental foi inteiramente casualizado, com cinco repetiçôes, sendo cada repetição constituída de um tanque. A água utilizada tanto nos experimentos de germinação quanto de submersão foi proveniente de poço artesiano do INPA. Durante o experimento foram avaliadas alterações nas características morfoanatômicas e no metabolismo das plântulas, associáveis ao alagamento.

\section{AVALIAÇÃO MORFOLÓGICA}

A morfologia externa e o estado geral das plântulas foram avaliados em intervalos de 15 dias. Foram feitas observaçôes visuais e anotaçôes da presença ou não dos seguintes sintomas: clorose das folhas, lenticelas nos caules e formação de raízes adventícias.

\section{ANÁLISES ANATÔMICAS}

Foram realizadas 60 dias após o início dos tratamentos. Raízes secundárias foram seccionadas por meio de cortes à mão-livre e as secçōes clarificadas em solução de hipoclorito de sódio $20 \%$, coradas com azul de astra e fucsina básica (Johansen, 1940). Foram feitas fotomicrografias em fotomicroscópio óptico modelo Zeiss MC63.

\section{ANÁLISES BIOQUÍMICAS}

A atividade da enzima do metabolismo anaeróbico $\mathrm{ADH}$ (E.C. 1.1.1.1) foi analisada nas raízes das plântulas de H. sucuuba nos intervalos de tempo: 0 (controle), 15, 30, 60, 90 e 120 dias, após o início dos tratamentos. A mistura de reação enzimática foi feita com base na metodologia descrita por Russell et al. (1990), com modificaçôes, sendo composta por $0,300 \mathrm{ml}$ de Tris-Cl 1 $\mathrm{M}(\mathrm{pH} 8,0), 0,040 \mathrm{ml} \mathrm{de} \mathrm{NAD}^{+} 10 \mathrm{mg} / \mathrm{ml}, 0,040 \mathrm{ml}$ de amostra e água para completar o volume final de $1,96 \mathrm{ml}$. Após a adição de $0,040 \mathrm{ml}$ de $50 \%$ etanol a mistura de reação foi invertida uma vez e a leitura espectrofométrica (Genway Instrument 6105) realizada a $A_{340} \mathrm{~nm}$.

\section{RESULTADOS E DISCUSSÃO}

Durante o período de observação da germinação, que durou cerca de 30 dias, nenhuma das sementes cujo revestimento alado foi mantido germinou, independente do substrato. Por outro lado, nas sementes em que foi feita a remoção destes revestimentos, deixando livre a região da micrópila, a germinação ocorreu em um período máximo de 15 dias. Desta forma, é plausível supor que, a exemplo do que se verifica em várias sementes de árvores tropicais, como as do gênero Podocarpus e algumas espécies de Parkia (Kozlowski et al., 1991; Scarano \& Crawford, 1992), em H. sucuuba o envoltório constitui-se em uma barreira para a germinação, embora seja de grande importância para a dispersão anemocórica e hidrocórica (Ferreira et al., 2005).

A espécie apresentou elevada taxa de germinação, independente do substrato utilizado (Fig. 1). No tratamento não-alagado (serragem+areia) a germinação foi de $94 \%$ e no tratamento de alagamento (água) $96 \%$, sendo essa diferença não significativa. No entanto, a submersão da semente diminuiu a produção de plântulas. Todas as sementes do tratamento nãoalagado que germinaram produziram plântulas (100\%). Entre aquelas que germinaram no tratamento de alagamento, somente $84 \%$ formaram plântulas (Fig. 1). A germinação e subseqüente crescimento de plântulas sob condiçôes de hipóxia causada por alagamento ocorre em outras espécies tropicais, como Inga affinis e Sesbania virgata (Lobo \& Joly, 1998), Mora paraensis, Vatairea guianensis, Crateva benthami, Nectandra amazonum (Parolin \& Junk, 2002) e Carapa guianensis (Scarano et al., 2003). Nas várzeas da Amazônia Central esse tipo de adaptação tem especial importância, uma vez que as plantas dispõem de um espaço de tempo limitado para germinar e fixar suas raízes no solo, antes da próxima inundação. Essas características mostram $H$. sucuuba como uma planta eficiente na colonização de ambientes expostos a inundaçōes prolongadas, conforme discutido por Ferreira $e t a l$. (2005).

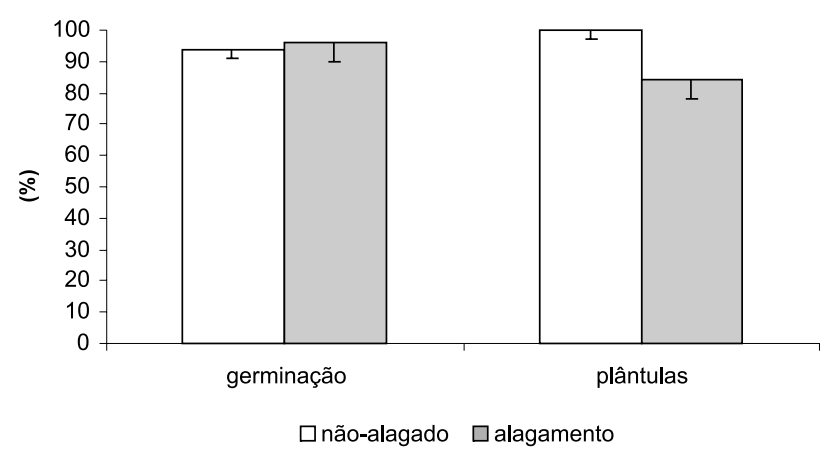

Figura 1 - Taxa de germinação e de produção de plântulas de $H$. sucuuba em substratos de areia+serragem (não-alagado) e em água (alagamento). $n=5$. $\perp$, erro padrão.

O número de espécies que consegue germinar sob anoxia é muito limitado (Crawford, 1992). A maioria delas corresponde a herbáceas adaptadas ao alagamento, como é o caso de algumas gramíneas dos gêneros Oryza e Echinochloa (Crawford, 1992; Lobo \& Joly, 1998) e da espécie Typha latifolia (Frankland et al., 1987). No entanto, a capacidade de germinar em condiçôes anaeróbicas não está restrita apenas a espécies aquáticas, conforme constatado em Chorisia speciosa, cujas sementes emitem radícula sob ausência total de oxigênio. Neste caso, a anoxia é condicionada pela presença de mucilagem nas sementes (Crawford, 1992; Lobo \& Joly, 1998). Contudo, para H. sucuuba é necessário a realização estudos para determinar se a espécie teria capacidade de germinar sob anoxia, o que seria de fundamental importância para definir os limites de tolerância da planta ao déficit de oxigênio, durante as primeiras fases de seu desenvolvimento. 
No tratamento controle e de submersão parcial, todas as plântulas sobreviveram até o final do experimento. A submersão parcial das plântulas induziu a formação de lenticelas hipertróficas e raízes adventícias, o que ocorreu a partir do $15^{\circ}$ dia. Após o $60^{\circ}$ dia essas estruturas mostraram-se bastante desenvolvidas (Fig. 2A). Esses caracteres morfológicos não ocorreram nas plântulas do tratamento controle. Clorose e abscisão das folhas não foram evidenciadas nas plântulas controle ou sob submersão parcial. Quando sob submersão total, as plântulas não apresentaram alteraçōes na morfologia externa do caule e tampouco formaram raízes adventícias. Uma vez que essas estruturas facilitariam as trocas gasosas com o meio aerado (Kozlowski, 1997; Mielke et al., 2003), elas não teriam função sob condições de submersão total da plântula. Neste tratamento, após quinze dias de submersão, as plântulas demonstraram sintomas de clorose nas folhas, seguidos de abscisão das mesmas. A submersão total da plântula ocasionou a morte de indivíduos ao longo do período experimental e, ao final dos 120 dias, o percentual de sobreviventes foi de $70 \%$.

O alagamento, tanto parcial quanto total, induziu a formação de grandes espaços na região do córtex das raízes de $H$. sucuuba, chamados de tecido aerênquima (Fig. 2B). Esse tecido é comumente desenvolvido em caules (hastes) e raízes de plantas que sofrem alagamento, sendo efetivo para oxigenação a grandes distâncias (Drew et. al., 2000; Gunawardena et al., 2001; Malik et al., 2004). As raízes com aerênquima podem ainda gerar estreitas zonas oxigenadas em sua rizosfera, em decorrência da difusão do $\mathrm{O}_{2}$ de seus espaços internos para a superfície externa da raiz (Kozlowski, 1997), o que aumentaria a tolerância da espécie a esses ambientes. Nas plântulas do controle essas estruturas não foram evidenciadas.

Sob submersão $H$. sucuuba desvia a via metabólica de aeróbica para anaeróbica, com produção de etanol. A ADH, enzima chave da via de fermentação alcoólica, foi verificada nas plântulas do controle, ainda que em baixas concentraçōes ( $36 \mu$ mol de NADH $\mathrm{g}^{-1} \mathrm{MF}$ ) (Fig. 3), indicando ser uma enzima constitutiva. Sob submersão parcial as plântulas exibiram valores médios mais elevados aos 15 dias $\left(136,2 \mu \mathrm{mol}\right.$ de $\left.\mathrm{NADH} \mathrm{g}{ }^{-1} \mathrm{MF}\right)$, que decresceram até o final do experimento de 120 dias $(98,4 \mu \mathrm{mol}$ de NADH g-1 MF). Esse resultado, provavelmente, está relacionado ao aparecimento de adaptaçôes morfológicas, como a formação de raízes adventícias e lenticelas nas plântulas que permaneceram neste tratamento. É comum que plantas tolerantes ao alagamento promovam interaçôes das adaptaçōes morfológicas e anatômicas, que permitam o transporte e armazenamento do oxigênio da parte aérea para as partes submersas da planta (Crawford, 1992; Mielke et al., 2003), com finalidade de garantir a manutenção dos processos fisiológicos essenciais.

Para as plântulas do tratamento de submersão total, o metabolismo foi totalmente anaeróbico, tendo sido ajustado gradativamente até um nível constante e elevado de atividade da
$\mathrm{ADH}$ (Fig. 3). Quando comparadas com outras espécies tolerantes, como o açaí (Euterpe oleracea), palmeira que coloniza solos encharcados na Amazônia (Menezes Neto, 1994), a atividade da $\mathrm{ADH}$ nas raízes de $H$. sucuuba mostrou-se superior, indicando esta via metabólica como o principal mecanismo da planta para manter a carga energética (Crawford, 1992). Uma estratégia comumente utilizada em situaçôes de baixos níveis de oxigênio (Geigenberg, 2003). No entanto, o produto final dessa via é o etanol, cujo acúmulo é tóxico às plantas, podendo ser letal para as espécies não tolerantes (Crawford, 1992; Kozlowski, 1997; Lobo \& Joly, 1998). As espécies que conseguem tolerar períodos longos de hipóxia e/ou anoxia necessitam desenvolver mecanismos que eliminem para o meio os produtos tóxicos formados na respiração anaeróbica (Crawford, 1992; Ellis et al., 1999). Neste tratamento, a sobrevivência das plântulas da várzea mesmo com a elevada atividade do metabolismo anaeróbico,
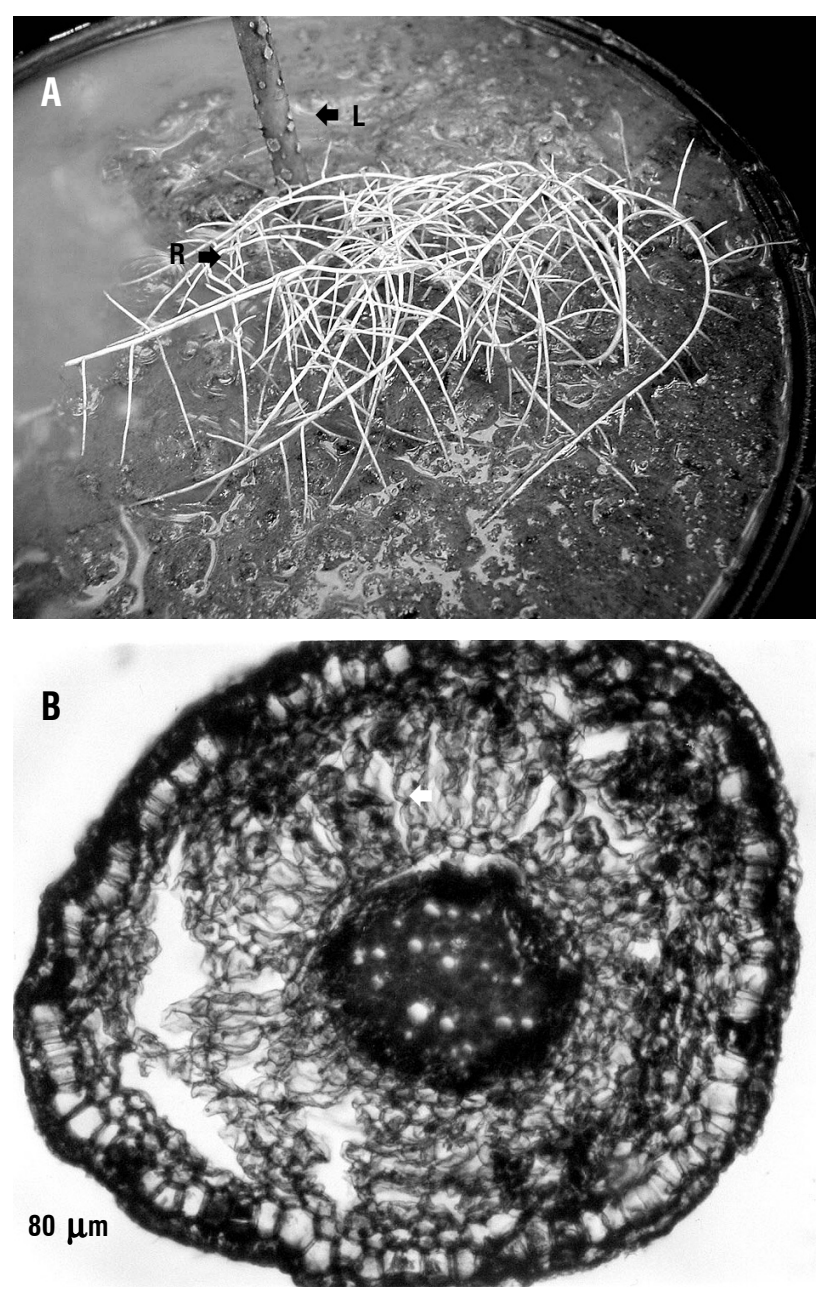

Figura 2 - Detalhes da plântula de H. sucuuba, após 120 dias de alagamento parcial, evidenciando as estruturas: A) lenticelas $=L$ e raízes adventícias $=\mathrm{R}$; B) aerênquima 
sugere que esta espécie dispõe de mecanismos eficientes de remoção desses produtos, indicando-a como tolerante ao alagamento. No entanto, esses mecanismos ainda são pouco conhecidos, merecendo, portanto, estudos adicionais para que seja possível identificar em $H$. sucuuba quais são e como agem.

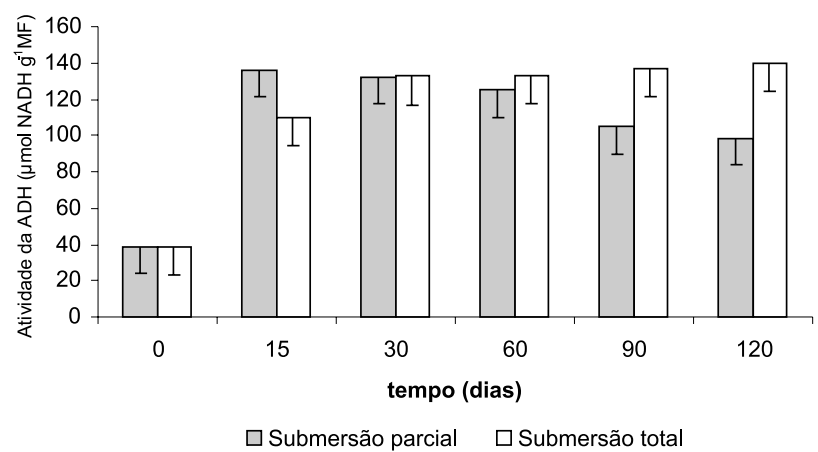

Figura 3 - Atividade da ADH em raízes de plântulas de $H$. sucuuba, submetidas ao tratamento de submersão parcial e submersão total. Média de três repetições. $\perp$, erro padrão.

\section{CONCLUSÃO}

Plântulas de $H$. sucuuba são tolerantes ao alagamento, evidenciado pelo sucesso nas taxas de germinação, de produção de plântulas e de sua sobrevivência. Contudo, os mecanismos de tolerância ao alagamento variaram em função do tempo de exposição ao estresse e altura da coluna de água. Em condiçōes de submersão parcial inicialmente ocorreu uma promoção da respiração anaeróbica e posteriormente o aparecimento de adaptaçôes morfológicas e anatômicas que facilitaram a difusão de $\mathrm{O}_{2}$ para as raízes. Em condições de submersão total, o incremento substancial da respiração anaeróbica e sua manutenção em níveis altos ao longo do tempo, sugerem a existência de mecanismos que promovem a desintoxicação da planta, propiciando a grande tolerância da espécie ao alagamento.

\section{AGRADECIMENTOS}

Ao Instituto Nacional de Pesquisas da Amazônia (INPA), ao Projeto INPA/Max-Planck pelo suporte financeiro, a CAPES pela concessão da bolsa de mestrado de Cristiane Ferreira, ao Dr. José Francisco Gonçalves, pesquisador do INPA, pelo auxílio nas análises bioquímicas e ao Sr. Valdeney de Araújo Azevedo pelo apoio técnico no campo.

\section{BIBLIGRAFIA CITADA}

Capon, S. J. 2005. Flood variability and spatial variation in plant community composition and structure on a large arid foodplain. Journal of Arid Environments, 60: 283-302.

Crawford, R.M.M. 1992. Oxygen availability as an ecological limit to plant distribution. In: Bergon, M.; Fitter, A.H. (Eds.). Advances in ecological research. Academic Press, London. p. 93185.
Dat, J. F., Folzer, N. C. H., Bourgeade, P., Badot, P. M. 2004. Sensing and signalling during plant flooding. Plant Physiology and Biochemistry, 42: 273-282.

Dennis, E.S.; Dolferus, R.; Ellis, M.; Rahman, M.; Wu, Y.; Hoeren, F.U.; Grover, A.; Ismond, K.P.; Good, A.G.; Peacock, W.J. 2000. Molecular strategies for improving waterlogging tolerance in plants. Journal of Experimental Botany, 51 (342): 89-97.

Drew, M.C.; He, C.; Morgan, P. W. 2000. Programmed cell death and aerenchyma formation in roots. Trends in Plant Science, 3(5): 123-127.

Ellis, M.H.; Dennis, E.S.; James, W. 1999. Arabdopsis root and shoots have different mechanisms for hipoxic stress tolerance. Plant Physiol., 119(1): 57-64.

Ferreira, C.S.; Piedade, M.T.F.; Parolin, P.; Barbosa, K.M.N. 2005. Tolerância da espécie Himatanthus sucuuba Wood. (Apocynaceae), ao alagamento na Amazônia Central. Acta Botanica Brasilica, 15: 100-112.

Frankland, B.; Bartley, M.R.; Spence, D.H.N. 1987. Germination under the water. In: Crawford, R.M.M. (Ed.). Plant life in aquatic and amphibious habitats. Special publication series of the British Ecological Society, Number 5. Blackwell Scientific Publications, Oxford, England. p. 167-178.

Geigenberger, P. 2003. Response of plant metabolism to too little oxygen. Current Opinion in Plant Biology, 6: 247-256.

Gunawardena, A.H.L.A.N.; Pearce, D.M.; Jackson, M.B.; Hawes, C.R.; Evans, D.E. 2001. Characterization of programmed cell death during aerenchyma formation induced by ethylene or hypoxia in roots of maize (Zea mays L.). Planta, 2(212): 205214.

Hook, D.D. 1984. Adaptations to flooding with fresh water. In: Kozlowski, T.T. (Ed.). Flooding and plant growth. Academic Press, New York. p. 265-294.

Johansen, D.A. 1940. Plant Microtechnique. Tata-MacGraw-Hill, Bombay. 523p.

Junk, W.J. 1993. Wetlands of tropical South-America. In: Whigham, D.; Hejny, S.; Dykyjová, D. (Eds.). Wetlands of the world. Kluve, Dordrecht. p. 679-739.

Junk, W.J.; Barley, P.B.; Sparks, R.E. 1989. The flood-pulse concept in river-floodplain systems. Can. Spec. Publ. Fish Aquat. Sci., 106: 110-127.

Kozlowski, T.T. 1997. Responses of woody plants to flooding and salinity. Tree Physiology Monograph, n. 1, p. 1-29.

Kozlowski, T.T.; Kramer, P.J.; Pallardy, S.G. 1991. The physiological ecology of woody plants. Academic Press, San Diego. 657p.

Lobo, P.C.; Joly, C.A. 1998. Tolerance to hypoxia and anoxia in Neotropical tree species. Oecologia Brasiliensis, 4: 137-156.

Lytle, D. A.; Poff, N. L. 2004. Adaptation to natural flow regimes. Trends in Ecology and evolution, 16(2): 94-100.

Malik, A. I., Colmer, T. D., Lambers, H., Schortemeyer, M. 2004. Aerenchyma formation and radial $\mathrm{O}_{2}$ loss along adventitious roots of wheat with only the apical root portion exposed to $\mathrm{O}_{2}$ deficiency. Plant Cell and Environment, 26: 1713-1722. 
Menezes Neto, M.A. 1994. Influência da disponibilidade de oxigênio sobre a germinação, crescimento, e atividade das enzimas álcool desidrogenase e lactato desidrogenase em Açaí (Euterpe oleracea Mart.). Dissertação de Mestrado, Escola Superior de Agricultura de Lavras, Minas Gerais, Brasil. 50p.

Mielke, M. S., Almeida, F. A. A., Gomes, F. P., Aguilar, M. A. G., Mangabeira, P. A. O. 2003. Leaf gas exchange, chlorophyll fluorescence and growth responses of Genipa americana seedlings to soil flooding. Environmental and Experimental Botany, 50: 221-231.

Parolin, P. 2000. Phenology and $\mathrm{CO}_{2}$-assimilation of trees in Central Amazonian floodplains. J. Trop. Ecol., 16(3): 465-473.

Parolin, P. 2001. Seed germination and early establishment of 12 tree species from nutrient-rich and nutrient-poor Central Amazonian floodplains. Aquatic Botany, 70: 89-103.

Parolin, P.; Junk, W.J. 2002. The effect of submergence on seed germination in trees from Amazonian floodplains. Boletim Museu do Museu Paraense Emílio Goeldi. Série Botânica, 18(2): 321-329.

Piedade, M.T.F.; Junk, W.W.; Parolin, P. 2000. The flood pulse and photosynthetic response of trees in a white water floodplain (várzea) of Central Amazon, Brazil. Verh. Internat. Verein. Limnol., 27: 1734-1739.

Piedade, M.T.F.; Worbes, M.; Junk, W.J. 2001. Geo-ecological controls on elemental fluxes in communities of higher plants in Amazonian floodplains. In: McClain, M. E., Victoria, R. L., Richey, J. E. (Ed.) The Biogeochemistry of the Amazon Basin. Oxford University Press, New York. p. 209-234.
Plumel, M.M. 1991. Le genre Himatanthus (Apocynaceae). Révision taxonomique. Bradea, 5: 118p.

Russel, D.A.; Wong, D.M.L.; Sachs, M.M. 1990. The anaerobic response of soybean. Plant Physiology, 92: 401-407.

Scarano, F.R.; Crawford, R.M.M. 1992. Ontogeny and the concept of anoxia-tolerance: the case of the Amazonian leguminous tree Parkia pendula. Journal of Tropical Ecology, 8: 349-352.

Scarano F.R., Pereira T.S.; Rocas G. 2003. Seed germination during floatation and seedling growth of Carapa guianensis, a tree from flood-prone forests of the Amazon. Plant Ecology, 168(2): 291296.

van den Berg, M.E. 1984. Ver-O-Peso: the ethnobotany of an Amazonian market. In: Prance, G.T.; Kallunki, J.A. (Eds.). Advances in Economic Botany. Ethnobotany in the Neotropics. New York Botanical Garden, Bronx, New York. p. 140-149.

Wittmann, F., Anhuf, D.; Junk. W.J. 2002. Tree species distribution and community structure of central Amazonian várzea forests by remote-sensing techniques. Journal of Tropical Ecology, 18: 805-820.

Recebido em 05/08/2006

Aceito em 23/11/2006 